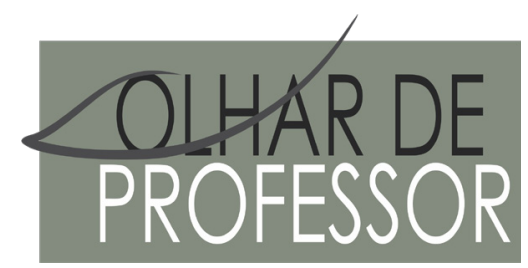

DOI: 10.5212/OLHARPROFR.v.23.2020.16585.209209228702.0807

\title{
INVESTIGAÇÃO TEMÁTICA FREIREANA E O ENFOQUE CTS NO ENSINO DE CIÊNCIAS: CURRÍCULOSE PRÁTICAS NO ENSINO FUNDAMENTAL
}

\author{
FREIREAN THEMATIC INVESTIGATION AND STS FOCUS IN SCIENCE TEACHING: CURRICULUMS \\ AND PRACTICES IN ELEMENTARY SCHOOL \\ INVESTIGACIÓN TEMÁTICA FREIREANA Y EL ENFOQUE CTS EN LA ENSEÑANZA DE CIENCIAS: \\ CURRÍCULOS Y PRÁCTICAS EN LA EDUCACIÓN FUNDAMENTAL
}

\section{GULLHERME SCHWAN ${ }^{*}$ ROSEMAR AYRES DOS SANTOS}

\begin{abstract}
Resumo: Este relato é produto de uma pesquisa de mestrado desenvolvida no Programa de Pós-Graduação em Ensino de Ciências - Universidade Federal da Fronteira Sul. A temática surgiu da implantação de uma usina hidrelétrica no município de Roque Gonzales, RS. O objetivo constituiu em construir possibilidades de práticas escolares e colaborar junto à educação CTS e os pressupostos de Paulo Freire, contribuindo na interação de professores das disciplinas de Ciências e Geografia, com trabalhos concretos em sala de aula, com estudantes do $9^{\circ}$ ano no Ensino Fundamental, em uma escola pública municipal situada no mesmo munícipio de implantação do empreendimento, utilizando questionários para a identificação de conteúdos, e como forma de contribuir na análise da prática, usamos diários de bordo com memórias do pesquisador e estudantes. Deste modo, procuramos estimular a participação docente no planejamento de aulas que tragam problemáticas reais da Ciência-Tecnologia e aos estudantes a emergirem de uma consciência ingênua para uma concepção crítica de sua realidade.
\end{abstract}

Palavras-chave: Freire. Ciência-Tecnologia-Sociedade. Ensino de Ciências.

Abstract: This report, is the product of a Master research, developed in a Graduate Program in Science Teaching - Federal University of Southern Boarder, The thematic came up from the installation of and hydroelectric power plant in Roque Gonzales, RS. The objective was to create possibilities of school practices and cooperate with STS education and Paulo Freire assumption, contributing in the interaction of Science and Geography teachers, with solid works in classroom, with students from the 9th grade in the Elementary School, in a municipal public school sited in the same city as the enterprise installation, using questionnaires to identify contents, and to contribute with the practice analysis, we used logbooks with students' and researcher's memories. Thus, we seek to stimulate teaching participation in class planning that brings real Science-Technology issues and the students to emerge from a naive consciousness, to a critical conception of their reality.

Keywords: Freire. Science-Technology-Society. Science Teaching.

Resumen: Este relato es producto de una investigación de maestría desarrollada en el Programa de Pós-Graduação em Ensino de Ciências - Universidade Federal da Fronteira Sul. La temática ha surgido de la inserción de una central hidroeléctrica en el municipio de Roque Gonzales, RS. El objetivo se ha constituido en componer posibilidades de

\footnotetext{
* Mestrando em Ensino de Ciências pela Universidade Federal da Fronteira Sul (UFFS). Professor de Ciências na rede municipal de ensino do município de Santo Ângelo/RS. E-mail: guilhermeschwan@gmail.com.

${ }^{* *}$ Doutora em Educação pela Universidade Federal de Santa Maria. Professora do Curso de Física Licenciatura e do Programa de Pós-Graduação em Ensino de Ciências, Universidade Federal da Fronteira Sul. E-mail: roseayres07@gmail.com
} 
prácticas escolares y colaborar junto a la educación CTS y los presupuestos de Paulo Freire, contribuyendo en la interacción de los profesores de las asignaturas de ciencias y geografía, con trabajos concretos en salón de clase, con estudiantes de $9^{\circ}$ grado de la educación fundamental, en una escuela pública municipal ubicada en el mismo municipio del emprendimiento, utilizando encuestas para la identificación de contenidos y como forma de ayudar en el análisis de la práctica, usamos cuadernos de registros con memorias del investigador y de los estudiantes. De esta manera, hemos buscado la participación docente en la planificación de clases que aborden problemáticas reales de la Ciencia-Tecnología y a los estudiantes emergieren de una ingenua conciencia para una concepción crítica de su realidad.

Palabras-clave: Freire. Ciencia-Tecnología- Sociedad. Enseñanza de Ciencias.

\section{INTRODUÇÃO}

O presente relato nasce a partir de uma proposta de configuração curricular escolar entre a abordagem temática freireana e o enfoque CTS, desenvolvido de forma interdisciplinar, na busca de um currículo democrático e participativo, formador de sujeitos críticos e transformadores de sua realidade, que vai desde a elaboração e planejamento de aulas, chegando ao desenvolvimento em sala de aula, ambas fundamentadas em características vivenciais, para que, nesta prática educativa, professores e estudantes possam tomar consciência de sua inconclusão, assim percebendo enquanto sujeitos históricos que são, não apenas adaptar sua presença ao mundo, mas inserir-se e o tornar possível de transformação (FREIRE, 2020).

Reforçando a ligação de um currículo crítico com a prática escolar, rompendo com o modo operacional que o currículo tradicional oferece, no qual diferentes sujeitos o concebem e outros (professores) o executam. Silva (2005) destaca que teorias tradicionais se concentram em formas de organização e elaboração do currículo, restringe-se na atividade técnica de como fazer o currículo, enquanto as teorias críticas enfocam os rearranjos sociais e educacionais.

Neste sentido que, a partir desta configuração curricular, afirmada na aproximação entre Freire e o enfoque CTS, buscamos proporcionar a maior participação deste segundo sujeito (professores), na formulação curricular escolar, que em uma perspectiva curricular prática, ligada ao mundo vivencial, o professor e o estudante são participantes ativos na construção e elaboração do currículo a partir de uma problemática social e ambiental, levando tais inserções para a sala de aula. A fim de maior contextualização dos conhecimentos, provocando o envolvimento dos estudantes, objetivando favorecer o posicionamento crítico, na construção de uma sociedade mais democrática, em que os estudantes possam se posicionar sobre questões que impliquem mudanças no seu mundo.

Para tanto, contemporaneamente, muitos pesquisadores - Auler (2002 e 2007), Auler et al. (2009), Roso et. al (2015), Santos (2016), Santos e Auler e (2019), Strieder (2008 e 2012), Rosa e Strieder (2018) - tratam da articulação em âmbito educacional do enfoque Ciência-Tecnologia-Sociedade (CTS) e os pressupostos de Paulo Freire, articulação ancorada pela abordagem por temas, sendo uma "perspectiva curricular cuja lógica de organização é estruturada com base em temas, com os quais são selecionados os conteúdos de ensino das disciplinas. Nessa abordagem, a conceituação científica da programação é subordinada ao tema" (DELIZOICOV; ANGOTTI; PERNAMBUCO, 2002, p. 189). Portanto, definindo o tema, através de um processo de investigação, este dará suporte para identificar quais conhecimentos/ conteúdos são necessários para o estudo da temática em sala de aula.

Nessa perspectiva, a aproximação entre Freire e CTS contribui na sustentação deste relato, pois perpassa exatamente na busca de temas/problemas condicionados pelo desenvolvimento da CiênciaTecnologia (CT), em que o educador Paulo Freire sugere a dinamização do processo educacional através da Investigação Temática na busca de temas geradores, os quais envolvam situações problemáticas, contraditórias, destacando a importância da utilização do diálogo e problematização como forma de obtenção dos temas e desenvolvendo como uma concepção dialógico-problematizadora da educação, contrária à educação "bancária”, que apenas realiza "depósitos” nos educandos, "meras incidências, recebem pacientemente, memorizam e repetem” (FREIRE, 1987, p. 37), uma prática desconexa ao mundo vivido pelos estudantes. 
Mesmo que na proposta original de Freire (1987) não exista preocupações diretas em questões curriculares, sua proposta é fundamentada na "dialogicidade" como essência da educação, como prática da "liberdade" (p. 50). Que nesta perspectiva, o diálogo é realizado com o educando e não sobre ele, muito menos dialogar sobre qualquer assunto, professor e estudante constroem uma relação dialógica a partir da problematização de sua realidade com vistas a formação crítica do educando.

Assim, nesse contexto, o tema gerador que nesta pesquisa foi a implantação de uma usina hidrelétrica no município de Roque Gonzales, Rio Grande do Sul - RS, a qual devido aos seus altos impactos ambientais, sociais, culturais e políticos que, em tese, são encobertos pela confiabilidade depositada na CT, configurando uma perspectiva salvacionista, enfatizando a CT como redentora, capaz de resolver todos os problemas, assim como de garantir o bem-estar social à população, ao mesmo passo que o determinismo tecnológico, que considera a tecnologia como um processo independente aos fatores sociais, esses sustentados pela suposta neutralidade em que a CT está ancorada e serve de sustentação às demais questões cientifico-tecnológicas não problematizadas.

Como é o caso de problemáticas ambientais, que é um dos focos do movimento CTS, que tem sua origem em meados do século XX, no Hemisfério Norte, "principalmente nos países ditos capitalistas, com o intuito do desenvolvimento do bem estar social, contrapondo-se à ideia de que mais Ciência e mais Tecnologia irão, necessariamente, resolver os problemas ambientais, sociais e econômicos' (SCHWAN; SANTOS, 2020, p. 03). Destacamos, como exemplo, a obra "Primavera Silenciosa", de Rachel Carson, em 1962, a qual faz um iminente alerta à saúde humana e à natureza, decorrentes do uso de um inseticida - DDT (Dicloro-Difenil-Tricloetano) ou, mais atualmente, com a publicação do livro "A Sexta Extinção: Uma História Não Natural” escrito por Elizabeth Kolbert, em 2014, o qual narra a extinção de várias espécies pala ação imprudente das atividades humanas e alerta para mais uma extinção em massa, a sexta! O que poderá ocasionar a nossa queda.

Mesmo os dois escritos não fazendo alusões ao campo CTS, alertam de como a ação humana influencia em questões ambientais e a mesma é influenciada por questões envolvendo CT, que passam a ser vistas, por parte da sociedade, como neutras, nos quais os pesquisadores/técnicos podem "solucionar os problemas, inclusive os sociais, de um modo eficiente e ideologicamente neutro” (AULER, 2003, p. 75). De certa forma, creditando a essa crença a desconexão entre fatores sociais de determinada classe, na consecução e desenvolvimento da CT, ou seja, a minoria de uma classe social dominante e opressora, possuidora de poder sobre os rumos da CT. Rumos que podem não advir de demandas da maior parte da sociedade oprimida, que, além de não compreender tais processos, é levada a sustentar uma postura de "fatalismo", que, para Freire (2020), trata-se de “[...] convencer-nos de que nada podemos contra a realidade social que, de histórica e cultural, passa a ser ou virar 'quase natural'(FREIRE, 2020, p. 21). Discussões estas que possuem um caráter educacional, pois partem para a análise de: como a sociedade é influenciada pelo desenvolvimento da CT ou que e quem determina os rumos dados ao desenvolvimento da CT?

Compreendendo a necessidade no campo educacional de trabalhar a CT como processo social e quais fatores que sucedem em seu desenvolvimento, voltamos à carga em uma discussão que, apesar de inicialmente não repercutir no âmbito educacional, como o movimento CTS originado nos países desenvolvidos do Hemisfério Norte, também, surge no mesmo período, porém sendo genuinamente um movimento de propósitos latino-americanos. O Pensamento Latino-Americano em Ciência-TecnologiaSociedade (PLACTS), o qual buscava a produção de Ciência-Tecnologia (CT) nacional que atendesse às demandas locais, tendo em vista que a importada de países ditos desenvolvidos “[...] não necessariamente seria adequada aos interesses e necessidades da população latino-americana, sendo, para eles, necessária uma reorientação da agenda de pesquisa em CT, de tal forma que essa incorporasse demandas e valores locais” (ROSO; AULER, 2016, p. 372). Uma crítica à linearidade em que a CT era transmitida pelos países denominados desenvolvidos. Ou seja, o PLACTS busca reorientação da Política de Ciência e Tecnologia (PCT) regional, que seja coerente com as demandas dos países latino-americanos. Uma Política PCT orientada pelas demandas das necessidades dos países da América Latina (DAGNINO, 2008).

Diante do exposto, o presente relato busca: Como desenvolver uma proposta prática em sala de aula a partir da aproximação dos pressupostos freireanos e referenciais do enfoque CTS, utilizando da investigação temática como dinâmica curricular? 
A partir da explanação da problemática, adentramos o objetivo deste trabalho, que é evidenciar e propor que problemáticas de cunho CTS possam adentrar espaços formais, as salas de aula, propondo, então, uma configuração curricular que resulta uma prática alicerçada no pressupostos freireanos e ao enfoque CTS, sendo práticas “[...] mais sensíveis ao entorno, mais abertas a temas, a problemas contemporâneos marcados pela componente científico-tecnológica” [...], sendo configuradas a partir de temas/problemas sociais relevantes, cuja complexidade não é abarcável pelo viés unicamente disciplinar (AULER, 2007, p. 02).

Assim, evidenciando novamente a aproximação entre Freire e CTS, que perpassa exatamente a busca de temas/problemas condicionados pelo desenvolvimento da CT. Sendo duas práticas complementares, enquanto PLACTS traz aprofundamentos da CT, Freire atua em aspectos educacionais. A referida aproximação, que para Auler; Delizoicov (2015) tem no seu ponto central a relação que FREIRE (1987) faz de "conhecimento crítico da realidade” com "uma leitura crítica do mundo", entrelaçando a necessidade de compreensão crítica em CTS. Do mesmo modo que, "para 'uma leitura crítica do mundo', para o 'desvelamento da realidade’, uma compreensão crítica sobre as interações entre ciência-tecnologia-sociedade foi considerada como fundamental” (AULER; DELIZOICOV, 2015, p. 281).

Contudo, esse relato não tem por propósito criticar de forma contundente seu funcionamento e seus impactos proporcionados pela usina hidrelétrica, mas contrapor e idealizar reflexões para planejamento de ações, em uma prática "aberta”, que esteja voltado a controvérsias da CT, e transpor para uma prática no contexto escolar, a qual demanda olhares profundos e críticos, e que, em longo prazo, possam estabelecer cientificamente opções de convívio harmonioso, intensificando a relação desses bens que promovem melhor condição de vida à sociedade, considerando a recuperação e a conservação do meio ambiente, promovendo ações conjuntas entre a escola e a sociedade.

Portanto, a escolha do tema: sobre a implementação de uma usina que aproveita o potencial hidrelétrico do rio para geração de energia, envolve diversas controvérsias científico-tecnológicas e socioambientais, principalmente acerca dos seus impactos, mostra-se pertinente. Como destacado, o tema envolve diversas questões controvérsias sócio/científicas que para Reis (1999) surgem dos impactos sociais provenientes de inovações científico/tecnológicas, dividindo a comunidade científica como a sociedade. Hoffmann e Duso (2012) ao analisar a significação do termo “controvérsias sociocientíficas”, utilizam as seguintes definições

(i) controvérsias que surgem dos impactos sociais de inovações científicotecnológicas que dividem tanto a comunidade científica, como a sociedade em geral; (ii) que permitam discussão entre duas, ou mais partes envolvidas sobre determinada controvérsia, na qual estão em jogo suas crenças e argumentações; (iii) se perante a controvérsia abordada, as pessoas possam se encontrar divididas, envolvendo juízos de valor que impossibilitam a sua resolução apenas através da análise das evidências ou da experiência (p. 02).

Visto que, balizados pelas questões controversas envolvendo a temática, estas passam a ser o ponto de partida para construir possibilidades de práticas escolares e contribuir para a educação CTS, proporcionando a interação de professores das disciplinas de Ciências e Geografia, que foram voluntários a desenvolver esta prática com trabalhos concretos em sala de aula, com estudantes do $9^{\circ}$ ano no Ensino Fundamental, em uma escola pública municipal, situada no mesmo munícipio de implantação do empreendimento, usando a interdisciplinaridade como ferramenta de contribuição e formulação curricular escolar.

Este relato é um produto de uma pesquisa de mestrado, o qual busca, através de uma proposta prática em sala de aula, desenvolver problemáticas vivenciais de estudantes, problemáticas com vistas à formação crítica do educando, "auxiliando a tomada de decisões e contribuindo na constituição de uma sociedade ética e democrática, que, em grande parte, são objetivos comuns ao enfoque CTS” (SCHWAN; SANTOS, 2020, p. 11) e dos pressupostos freireanos. 


\section{CARACTERIZAÇÃO DO CONTEXTO}

Buscamos, como campo de pesquisa, situações significativas, tanto para estudantes e professores, como para uma configuração curricular, a qual enfatizasse uma situação social significativa, com isso problematizar a partir do diálogo, conhecimentos e vivências aos conhecimentos formais escolares.

Desta forma, optamos por desenvolver esta intervenção em uma escola de ensino fundamental, localizada no município de Roque Gonzales - RS, escolha que advém de um processo de investigação sobre a pouca problematização dos efeitos provocados pela implementação da Usina Hidrelétrica (UHE) Passo São João, e pode gerar até 77 megawatts (MW), a qual foi implantada no mesmo município, provocando diversas alterações ambientais e sociais nesta região.

A UHE Passo São João entrou em operação no ano de 2012 no Rio Ijuí no Município de Roque Gonzales, localizada a aproximadamente 550 km de Porto Alegre (RS). Sua área de alagamento (reservatório) abrange também os municípios de São Luiz Gonzaga, São Pedro do Butiá e Rolador, na região Noroeste do Estado. A Usina Passo São João funciona a fio d'água, ou seja, seu reservatório tem somente a função de manter o desnível necessário para a geração de energia. A usina é constituída de uma barragem que utiliza um canal de adução para conduzir a água até a casa de força, de forma a aproveitar a queda natural do rio Ijuí. Esta UHE faz parte de um sistema de usinas em cascata no Rio Ijuí, sendo precedida pela UHE São José, no município de Cerro Largo (CARDOSO; DAMBRÓS; XAVIER; WEISS; GAUER, p. 04, 2015)

A escola, na qual foi realizada a prática, pertence à rede pública do município de Roque Gonzales. Os participantes foram delimitados a treze (13) estudantes do $9^{\circ}$ ano do ensino fundamental, e dois (2) professores (as), das disciplinas de Geografia e Ciências, ambos da mesma escola.

\section{DESENVOLVIMENTO DA PESQUISA}

Este relato resulta do desenvolvimento e implementação da proposta de abordagem temática fundamentada nos pressupostos freireanos (FREIRE, 1987) e pressupostos CTS (AULER, 2002; SANTOS, 2012, 2016), (SANTOS; AULER, 2019), (STRIEDER, 2008, 2012).

Neste aspecto, mostra-se pertinente uma breve explanação de todo o desenvolvimento da proposta de pesquisa ${ }^{1}$, a qual resultou neste trabalho. A proposta foi fundamentada na abordagem temática freireana, a qual é desenvolvida em cinco etapas, conforme sistematizado por Delizoicov, Angotti e Pernambuco (2002), a partir do terceiro capítulo da obra Pedagogia do Oprimido, de Paulo Freire (1987). Sinteticamente, as etapas correspondem a:

a) Primeira: - levantamento preliminar - que consiste em reconhecer o contexto sócio-histórico-econômico-cultural em que vive o estudante; b) Segunda: - análise das situações e escolha das codificações - escolha de contradições vividas pelo estudante que expressam de forma sintetizada o seu modo de pensar e de ver/interagir com o mundo, bem como a escolha de codificações; c) Terceira: - diálogos decodificadores - obtenção dos Temas Geradores a partir da realização de diálogos descodificadores; d) Quarta: - Redução Temática - trabalho em equipe interdisciplinar, com o objetivo de elaborar o programa curricular e identificar quais conhecimentos são necessários para o entendimento dos temas; e) Quinta: - desenvolvimento do programa em sala de aula.

Esclarecendo que a primeira, segunda e terceira etapas foram desenvolvidas e definidas previamente, pois um dos pesquisadores deste trabalho estava inserido no contexto escolar, desenvolvendo na época o trabalho de monitor de educação e, a partir de observações e participações na vida ativa escolar destes estudantes e professores (as), pode conhecer o contexto de suas vivências e estabelecer suas contradições. Havia a crença generalizada de que a implementação da usina abarcaria qualquer efeito negativo no ambiente, pois proporciona um local propício ao convivo social e de entretenimento à comunidade que frequenta a "prainha", como era chamado o local de inundação. Pelo estabelecimento de diálogos

\footnotetext{
${ }^{1}$ A presente pesquisa teve aprovação conforme as diretrizes do Comitê de Ética em pesquisa CAAE: 15178819.0.0000.5564.
} 
descodificadores, surgiu o "tema gerador", o qual aborda os impactos ambientais e sociais da implementação da Usina Hidrelétrica Passo São João.

Sendo assim, a pesquisa focava, principalmente, na quarta e quinta etapa da investigação temática. A quarta etapa envolveu o trabalho de professores (as) de diferentes disciplinas formando a equipe interdisciplinar, havendo a elaboração curricular (planos de aula). Em sua etapa inicial de elaboração, optou-se por aplicar um questionário aos estudantes, para dessa forma contribuir na construção do planejamento de aulas, identificando previamente alguns conhecimentos necessários para a compreensão da temática.

O questionário deteve-se em 10 questões: 1- No município de Roque Gonzales está localizada a usina Hidrelétrica "Passo São João", quais seus conhecimentos sobre ela? 2- Para você, quais contribuições que essa usina trouxe até a comunidade de Roque Gonzales? 3- Na época de instalação, sua família foi atingida de algum modo e/ou conhece alguma que foi? Explique como foi. 4- Por que você acha que foi escolhido esse local para construção da Usina no rio Ijuí, em parte no município de Roque Gonzales? 5- Para você, como funciona a usina hidrelétrica? 6- Devido à construção e agora o funcionamento da usina, ao ver estas mudanças ambientais, estão associadas a algum tipo de impacto? 7- Você sabe de onde vem a energia elétrica utilizada em sua casa e na escola? Na sua concepção, a capacidade de geração de energia da Usina compensa as mudanças socioambientais causadas por ela? 8- Quais outras formas de obtenção/geração de energia você conhece? 9- Os conteúdos escolares, apresentados em livros ou diferentes materiais, comtemplam apropriadamente, em seu entendimento, as questões socioambientais em relação à geração de energia por Usinas Hidrelétricas? 10- As diferentes tecnologias, como as utilizadas na usina hidrelétrica, podem prejudicar a sociedade que faz uso dela? Como?

Para, neste momento, resumir a análise das respostas dos estudantes, elaboramos o quadro 1, o qual sintetiza os conhecimentos usados na confecção dos planos de aula, advindos das respostas dos estudantes, conhecimentos presentes na discussão dos resultados deste relato, daí a importância de, sinteticamente, apresentá-los.

QUADRO 1:CONTEÚDOS PRÉVIOS, PROVENEENTES DA ANÁLISE DO QUESTIONÁRIO, UTLLIZADOS NA CONFECÇÃO DE PLANOS DE AULAS, २०२०.

\begin{tabular}{|c|c|}
\hline Questões & Conteúdos pós-análise \\
\hline Questão n 1 & $\begin{array}{l}\text { - Localização. } \\
\text { - Tipo de Usinas Hidrelétricas implementada na região (fio-água). } \\
\text { - Aspectos sociais e econômicos (geração de empregos). }\end{array}$ \\
\hline Questão n ${ }^{\circ} 2$ & $\begin{array}{l}\text { - ‘Produção’ de energia - comparativo entre diferentes Usinas Hidrelétricas. } \\
\text { - Aspectos sociais e econômicos (geração de emprego e renda ao município). }\end{array}$ \\
\hline Questão nº 3 & - Impactos sociais (remanejamento de moradores, próximos as áreas de alagamento). \\
\hline Questão n ${ }^{\circ} 4$ & $\begin{array}{l}\text { - Definição do local de instalação. } \\
\text { - Relevo. } \\
\text { - Declive. } \\
\text {-Fatos históricos da implementação da Usina Hidrelétrica, pesquisas em diversas fontes } \\
\text { (jornais, internet e relatos de moradores). }\end{array}$ \\
\hline Questão n ${ }^{\circ} 5$ & $\begin{array}{l}\text { - Energia. } \\
\text { - Energia potencial gravitacional. } \\
\text { - Energia cinética. } \\
\text { - Energia elétrica. } \\
\text { - Carga elétrica. } \\
\text { - Eletromagnetismo. } \\
\text { - Fluxo/vazão. }\end{array}$ \\
\hline Questão n ${ }^{\circ} 6$ & $\begin{array}{l}\text { - Fauna e Flora da região. } \\
\text { - Impactos ambientais influenciados na construção e agora funcionamento da Usina Hidrelétrica. } \\
\text { - Processo de transposição de peixes em época reprodutiva. } \\
\text { - Responsabilidade pelo funcionamento e mitigação de impactos ambientais. "Quem responde?” }\end{array}$ \\
\hline
\end{tabular}


conclusão

\begin{tabular}{|c|c|}
\hline Questões & Conteúdos pós-análise \\
\hline \multirow{5}{*}{ Questão n ${ }^{0} 7$} & - Energia - da usina até as residências. \\
\hline & - Unidades de medidas. \\
\hline & - Levantamento do ‘consumo’ diário residencial/escola (medidas de economia de energia). \\
\hline & $\begin{array}{c}\text { - A usina abastece quantos municípios, é viável comparado a seus impactos ambientais, como } \\
\text { quantificar tais impactos ambientais? }\end{array}$ \\
\hline & $\begin{array}{c}\text { - Questões de escassez de recursos naturais (água) e suas influências na ‘produção’ de energia/ } \\
\text { levantamento climático. }\end{array}$ \\
\hline \multirow{8}{*}{ Questão nº 8} & - Energias renováveis ou não renováveis. \\
\hline & - Diferentes formas de obtenção de energia a partir de: \\
\hline & Biomassa. \\
\hline & Eólica. \\
\hline & Solar. \\
\hline & Geotérmica. \\
\hline & Nuclear. \\
\hline & Hidrelétrica. \\
\hline \multirow{2}{*}{ Questão n ${ }^{\circ} 9$} & - Pesquisa. \\
\hline & - Visitação à Usina Hidrelétrica Passo São João. \\
\hline \multirow{2}{*}{ Questão $n^{0} 10$} & - Pesquisa. \\
\hline & - Visitação à Casa da Memória. \\
\hline
\end{tabular}

FONTE: SCHWAN; SANTOS, 2020.

Após a delimitação dos conhecimentos, passou-se para a segunda etapa da construção dos planejamentos de aula, a qual seguiu os "Três Momentos Pedagógicos que Delizoicov, Angotti e Penambuco (2002), assim os caracterizam:

Problematização inicial: apresentam-se situações reais que os alunos conhecem e presenciam e que estão envolvidas nos temas [...]. Organiza-se esse momento de tal modo que os alunos sejam desafiados a expor o que estão pensando sobre as situações. A meta é problematizar o conhecimento que os alunos vão expondo, de modo geral, com base em poucas questões propostas relativas ao tema e às situações significativas [...]. Organização do conhecimento: os conhecimentos selecionados como necessários para a compreensão dos temas e da problematização inicial são sistematicamente estudados neste momento, sob a orientação do professor. Aplicação do conhecimento: destina-se, sobretudo, a abordar sistematicamente o conhecimento que vem sendo incorporado pelo aluno, para analisar e interpretar tanto as situações iniciais que determinam seu estudo como outras situações que, embora não estejam diretamente ligadas ao motivo inicial, podem ser compreendidas pelo mesmo conhecimento (p. 200-202).

Portanto, os planejamentos tanto da disciplina de Geografia como da disciplina de Ciências, encontram-se estruturados nos Três Momentos Pedagógicos. Ao término dos planejamentos, iniciamos a quinta etapa da investigação temática - desenvolvimento do programa em sala de aula, na qual o pesquisador acompanhou todas as inserções das duas disciplinas, em um total de 14 horas/aula. Para contribuir na análise utilizamos diários de bordo, com memórias do pesquisador e estudantes. Para Porlán e Martín (1997), o uso do "diário", como recurso metodológico, permite refletir sobre os processos mais significativos no qual o autor está imerso.

Es una guía para la reflexión sobre la práctica, fayoreciendo la toma de conciencia del professor sobre su proceso de evolución y sobre sus modelos de referencia. Favorece, también, el establecimiento de conexiones significativas entre conocimiento práctico y conocimiento disciplinar, lo que permite una toma de decisiones más fundamentada. (p. 23). 
Em seguida, descreveremos e analisaremos as práticas em sala de aula, bem como algumas das respostas dos estudantes. Para tanto, entendemos que uma breve explanação sobre a totalidade da pesquisa se fez necessária, como, por exemplo, o processo de construção dos planos de aula, o que contribuirá para maior compreensão dos fatos a seguir explicitados sobre a prática em sala de aula.

Como já referido, participaram da pesquisa um total de 13 estudantes e 2 professores (as). Para contribuir na identificação dos sujeitos da pesquisa, utilizamos códigos alfanuméricos, tanto para a descrição do questionário, identificando os estudantes como E1, E2... E13, bem como de suas memórias. Os professores (as) serão identificados como "P1", para o (a) Professor (a) da disciplina de Geografia e P2 para o (a) Professor (a) da disciplina de Ciências.

\section{RESULTADOS}

Para iniciar o detalhamento e análise das atividades, destacamos as falas dos (as) professores (as) e estudantes em formato itálico, e, para melhor visualização, destacamos os conhecimentos do quadro 1 apresentados nos resultados, em negrito. Por opção cronológica do desenvolvimento da prática, optamos por iniciar pela disciplina de Geografia.

A abertura da aula teve breve explanação do projeto de pesquisa, do que seria trabalhado com a turma e sobre a participação de um dos pesquisadores em sala de aula, que era apenas acompanhar, sem intervenções. Após a apresentação, deu-se início aos conhecimentos investigados a partir das respostas dos estudantes, mais o acréscimo de conhecimentos que o (a) professor (a) P1 entendia como necessário a partir do tema, o que FREIRE (1987) denomina de redução temática, em que cada "especialista busca os seus núcleos fundamentais, os quais constituem as unidades de aprendizagem” (p. 73).

Portanto, primeiramente localizando a usina a partir de imagens aéreas e a localização do conjunto de obras que a compõem, a maioria dos estudantes relembrou a visita anterior à usina, promovida pela escola, em sua "semana do meio ambiente; por uma educação ambiental para além da sala de aula". Esse fator foi determinante para a rápida localização do empreendimento. Junto às imagens aéreas, foi localizada pelos estudantes a implantação de uma pequena e antiga usina já instalada (ainda em funcionamento), na qual surgiram os primeiros questionamentos: "Quem a construiu? Quem administra? Pra onde vai a energia"? (E).

O questionamento realizado pela maioria dos estudantes demonstrou o desconhecimento desta pequena usina, há muito tempo na região, e aos que conheciam a sua existência, não possuíam o real conhecimento da sua funcionalidade, tendo ela (usina), apenas como uma pequena barragem. Ainda em relação às imagens, relembrou-se a explicação realizada na visita e o motivo da escolha do local apropriado pra a instalação da usina, conhecimento da disciplina identificado na questão 1: localização; paisagem/ relevo do local, tipo de usinas hidrelétricas implementada na região (fio-água), destacando a utilização já de conhecimentos científicos na explicação, como "a força da água devido à queda”. (P1). "A velocidade de escoamento, para girar as turbinas". (P1). Também foi explicado o tipo de usina instalada no município, se de fio d’água ou acumulação, no caso da usina em estudo "fio d’água", explicando que o relevo característico do município e da região impossibilita uma barragem do tipo acumulação.

Dando continuidade, o (a) P1 promoveu um debate e solicitou a comparação entre duas reportagens disponíveis em sites de acesso público², sobre a implantação, início das construções em 2006 e sobre o funcionamento/término em 2012. No primeiro momento, os estudantes identificaram a potência instalada da usina de 77 MW, sem maiores indagações, porém o fato que mais chamou a atenção (de estudantes) foi a estimativa de custos previstas ao início e seus custos ao final da operação, que superaram o dobro do previsto. "Como podem errar tanto na conta? Quem promoveu essa pesquisa”? (E3).

Tais indagações propuseram o início de outras problemáticas encontradas ao final dos trabalhos de construção apontadas pelos estudantes, como a inadequação na limpeza, tanto da flora, esta que ainda nos dias de hoje é possível ser visualizada, com restos de troncos e galhos na área de alagamento, e procedimento

\footnotetext{
${ }^{2}$ Reportagens disponíveis em: https://estado.rs.gov.br/obras-da-usina-passo-sao-joao-comecam-no-ultimo-trimestre-do-ano; e https://wp.clicrbs.com.br/noroestemissoes/2012/03/21/usina-hidreletrica-passo-sao-joao-de-roque-gonzales-comeca-a-operar/
} 
de retirada da fauna. "Eu não vi nada de animais sendo retirada (E12). Essa fala não foi somente uma afirmação dos fatos realmente ocorridos, mas de desconhecimento por parte dos estudantes e provavelmente do restante da população, por até o presente momento não ter acesso a informações, adquirindo-as pelas indagações realizadas pelo P1, as quais demonstraram, justamente, o papel do professor problematizador, que é “[...] proporcionar, com os educandos, as condições em que se dê a superação do conhecimento no nível da “doxa” pelo verdadeiro conhecimento, o que se dá, no nível do 'logos’” (FREIRE, 1987, p. 45).

Neste momento, também, pode-se notar a contribuição da análise do questionário (etapa antecedente ao planejamento, que teve por objetivo estabelecer conhecimentos iniciais), como as indagações relativas à geração de empregos, em que 5 estudantes acenaram a construção e funcionamento da UHE Passo São João como base para geração de empregos, como destacado pelo E8: "Inclusive minha mãe limpa a usina". Associando a este suposto e substancial aumento de empregos ao desenvolvimento do sistema econômico do município, negando qualquer impacto produzido pela UHE, evidenciado pelo E11: "Não, isso é crescimento para a cidade".

Geração de empregos que ganhava grande destaque nas matérias, e não condiziam com a realidade, pois devido à visita (projeto promovido anteriormente pela escola), os estudantes, constaram que havia efetivamente 12 funcionários na Usina. O (a) P1 explicou que a "geração de empregos era temporária, e após a construção este número despencaria, pois não haveria a necessidade, não teria tanto serviço para todos". Assim, surgindo uma nova indagação: "Porque a matéria não explicou isso"! (E4).

Destacando a reflexão feita pelos estudantes, de que a matéria apresentou apenas fatos positivos, omitindo a realidade em prol da instalação. Já, quanto aos resultados sobre a mitigação dos impactos ambientais, em site oficial da instituição, apenas enfatiza a explicação das ações realizadas pela Usina, não apontando os resultados. Importante destacar que tais questionamentos, vieram a enfatizar a não neutralidade dos fatos que envolvem aspectos da CT, no caso das informações (matérias) repassadas à sociedade, fato muito discutido e problematizado pela turma. Neutralidade da CT que está entendida como o isolamento dos conceitos em relação ao ambiente em que são gerados, ou seja, a produção científico-tecnológica é independente do contexto social, assim evitando que técnicos ou especialistas, os autores que promovem o desenvolvimento de mais CT, percebam o interesse de determinados grupos, que podem dar rumos diferentes à inovação (SANTOS, 2012).

Voltando ao questionamento da efetiva produção de energia da usina, indagou-se se "a energia produzida, era suficiente para abastecer o nosso município”? (E4). Pergunta já esperada pelo professor, pois, após a análise do questionário, houve, na resposta do E10, conhecimentos superficiais sobre a distribuição da energia elétrica brasileira; "A usina produz essa energia e manda para uma sede, e dessa sede é distribuída para as casas, escolas etc". Conhecimento introduzido pelo (a) P1 antecedentemente ao seu plano como conhecimento de linhas de transmissão, elucidando que a energia produzida na usina era repassada para todo o Brasil pelo sistema, utilizado - buscando comparações com a usina de Itaipu - a compra de parte da energia do Paraguai para suprir o abastecimento brasileiro - a história e motivo da utilização deste sistema (devido a muitos apagões ocorrido em tempos passados), e o único estado a não participar deste sistema (Roraima), que compra energia exclusivamente da Venezuela. Ampliando a discussão, são cabíveis comparações.

Outro tema que surgiu após as polêmicas quanto à necessidade da implantação da usina, foi a retirada de moradores das áreas de inundação e as Políticas sociais de ressarcimento adotadas pela empresa, aos municípios atingidos. O (a) P1 prontificou-se a buscar moradores, para uma fala em sala de aula, do todo o processo de retirada destes. Por sugestão dos estudantes, surgiu a ideia de uma visita até a "Casa da Memória”, situada em Roque Gonzales³, para a visitação e conhecimento da história de implantação da usina. "Vamos em lugares em que não tem sentido, e lá não vamos para conhecer isso"! (E4). A visita à Casa da Memória levantou diferentes questionamentos, principalmente sobre a colonização do município (alemã). Aproveitando o momento, o (a) P1 indagou a turma sobre a economia do município, que anteriormente à instalação e em dias atuais gira em torno da agricultura: "Quais as consequências da inundação de áreas agricultáveis para o município”? Utilizando o exemplo de uma comunidade no

\footnotetext{
${ }^{3}$ Espaço físico dedicado à manutenção da memória social e cultural dos residentes dos cinco municípios atingidos pelo lago da Hidrelétrica (Roque Gonzales, Dezesseis de Novembro, São Luiz Gonzaga, Rolador e São Pedro do Butiá).
} 
interior do município "Poço Preto”, com a maior área agricultável e muito importante economicamente ao município. Assunto que chegou à administração da usina, a qual no município de Roque Gonzales é de gestão pública.

O diálogo que mais chamou a atenção dos estudantes na visita à casa da memória foi a retirada dos moradores das áreas inundadas, seu impacto social, relatado pelo próprio funcionário responsável por tomar conta da Casa da Memória, que foi um antigo morador (M) de uma das áreas. "Dói muito"! (M). "Haviam planos para o futuro"! (M). "Não houve grande assistência”! (M), indagou o funcionário/ morador. Continuando sua explanação, comentou sobre a proibição de acesso ao "Salto Pirapó” (queda de água do rio Ijuí, que está a jusante da barragem), desde a construção da Usina, este que era ponto turístico do município de Roque Gonzales, no que surge a exclamação do professor (frequentador assíduo do salto antes de sua proibição) “Tudo isso foi 'roubado' de vocês”!(P1). "Tão pertinho e eu nunca fui até lá, e como parece ser bonito”! (E2).

No decorrer da fala, surgiram muitos comentários de alguns agricultores retirados do interior do município, que não conseguiram outras terras e "tiveram que competir no mercado de trabalho na cidade". (M). "O leiteiro que fazia a linha de leite, não tinha mais serviço, não demorou acabou morrendo, só sabia fazer isso". (M). Tais relatos comoveram muito os estudantes, quanto aos grandes impactos sociais gerados, os quais indagaram do "por que não falaram, que não queriam vender, nem sair das suas casas". (E4). Provocando a explicação do (a) P1, de que já "não era uma questão de escolha, devido as implicações e legislações do estado". Ressaltar que este diálogo surge de indagações proferidas pelo (a) P1, pois identificou a necessidade desta discussão nas respostas dos estudantes para a questão de número 6, como: "Os moradores das margens que tiveram que se retirar". (E10). "Interferência do homem, saída das pessoas”. (E12).

Ao término da visita e como de costume ao início de uma nova aula, são relembrados fatos ocorridos em aulas passadas, como: o funcionamento da UHE Passo São João, suas vantagens e desvantagens, impactos sociais, ambientais, perspectivas econômicas "na visão da mídia". Destaca o E4, questionamento que apontou reflexões críticas, de como é realizada a abordagem informativa sobre a implantação da usina pelos meios de comunicação. Outra lembrança dos estudantes foi a transformação da paisagem, fato que provocou novo questionamento sobre evento ocorrido em um diferente local que gerou grande modificação da paisagem: "a barragem de Brumadinho o que era”? (E1). Prontamente, o (a) P1 ofereceu a explicação de que se tratava de uma barragem de rejeitos de mineração, e devido à precária construção e manutenção/fiscalização houve o rompimento, causando diversos impactos, inclusive mortes e destruição de fauna e flora.

Assim, é interessante enfatizar como o tema inicial pode levar a diversos novos temas, com certa similaridade e ligação em diferentes aspectos, como a seguinte discussão, gerada sobre um dos diálogos de aulas anteriores, referente ao "tipo" de barragem da UHE Passo são João (Fio d'água), lembrou-se tanto de impactos sociais, ambientais e econômicos, e este último provocou a lembrança de seu superfaturamento, o qual quase dobrava seus valores iniciais de gastos. "Quem paga isso"? (E8). Lembrando, novamente, que tais diálogos estavam previstos já em planejamentos do (a) P1, na oportunidade, comparando a UHE Passo São João e a UHE São José, situada em parte no município de Cerro Largo, pois ambas estão localizadas no rio Ijuí e, por serem usinas de fio d’água, porém de diferentes administrações e diferentes investimentos, a primeira com investimento de 210 milhões (administração pública) ${ }^{4}$ e a segunda de 140 milhões (administração privada) ${ }^{5}$ segundo matéria ${ }^{6}$ veiculada em site do governo estadual do Rio Grande do Sul.

\footnotetext{
${ }^{4}$ UHE Passo São João, administrada pela Eletrosul Centrais Elétricas S.A., controlada da Eletrobras. Disponível em: http://www. eletrosul.gov.br/sala-de-imprensa/noticias/retorno-a-geracao-eletrosul-inicia-operacao-de-hidreletrica-no-rio-grande-do-sul.

${ }^{5}$ UHE São José, administrada pela Ijuí Energia S/A é uma “SPE - Sociedade de Propósito Específico”, O Contrato de Concessão de Serviço Público para Geração de Energia Elétrica nº 006/2006-MME-UHE São José, datado de 15 de agosto de 2006, celebrado com a União, por intermédio da Agência Nacional de Energia Elétrica - ANEEL outorgou à Companhia, a concessão de Serviço de Geração de Energia Elétrica, pelo prazo de 35 anos (até 14 de agosto de 2041), que consiste na exploração do potencial de energia hidrelétrica localizado no Rio Ijuí. Disponível em: http://ijuienergia.com.br/empresa/.

${ }^{6}$ Matéria disponível em: https://www.estado.rs.gov.br/usinas-passo-sao-joao-e-sao-jose-recebem-licenca-previa-da-fepam
} 
Na explicação do (a) P1, sobre o fato de uma apresentar um elevando custo em relação a outra, poderia advir de que a UHE São José tem como capacidade de geração de energia 51 megawatt (MW) e a UHE Passo São João de 77 MW, demandando maior investimento. Mesmo com a explicação do (a) P1, os estudantes ainda demonstraram interesse ao modelo de administração adotado pelas empresas responsáveis das UHEs, gerando grande embate entre eles quanto à eficácia da administração pública ou privada. "Tu preferes a privatização"? (E2). Referindo-se ao professor quanto à preferência ou não de privatizações das empresas brasileiras.

A discussão atingiu amplitude inimaginável nesta aula. O (a) P1 iniciou a explicação de acordo com a pergunta do E2, de como são os processos de privatização das empresas nacionais, remetendo a estudos proferidos antes deste projeto, como industrialização, mão de obra barata, pouquíssimos investimentos na educação. Problemática que causou a reflexão, chegando ao debate sobre a relação do Produto Interno Bruto (PIB) e Í́ndice de Desenvolvimento Humano (IDH) de países desenvolvidos, utilizando os Estados Unidos (EUA), com o maior PIB mundial (e com grande vantagem aos demais) e seu IDH muito baixo, a competitividade entre países com maior PIB provocando a "guerra comercial, evitando o comércio com países concorrentes" (P1).

Tais explicações conectadas de aulas passadas, até anteriores ao projeto, notando-se grande participação dos estudantes, pois estavam cientes sobre a questão, agora abordada com diferente viés, deixando de ser apenas um conteúdo definido a priori e indicado em livros didáticos sem atribuição de sentido, para provocar sentido a partir de uma temática relevante e desencadeadora de novos conhecimentos, no sentido de significados e objetivos que no momento, são atribuídos a eles. Após a discussão, destaco algumas reflexões dos estudantes: "Adianta todo esse dinheiro acumulado com IDH tão baixo"? (E5). Referindo-se à exploração da mão de obra barata e pouca escolarização: "Por isso, a importância da educação"! (E4). Destacando a importância da educação de qualidade, atentando-se para os fatos antes não percebidos, como o exemplo de poucos investimentos em educação, provocando alienação da sociedade a fatos prejudiciais. "Explicado porque as escolas estão tão ruins"! (E8). Referência feita à situação precária de algumas escolas brasileiras e salários atrasados de professores.

Assim, demonstrando como práticas significativas ao contexto dos estudantes podem contribuir com maior participação, consequentemente julgamentos conscientes e críticos de problemáticas para posterior intervenção na tomada de decisões, objetivo de uma real participação democrática, aspecto compartilhado pela aproximação Freire-CTS, na qual existe a necessidade crítica da realidade, para não limitar a ação da sociedade a apenas os impactos produzidos pela CT, mas também potencializar os processos decisórios (SANTOS, 2016).

Nessas aulas da disciplinas de Geografia, passadas as observações, é notório o desenvolvimento de questões emergentes no decorrer da aula a partir dos estudantes, apesar do planejamento prévio demonstrar grande valor, pois este desencadeou, no transcorrer da aula, a problematização de diversos temas ligados à temática central, a importância da mídia na formulação das informações ou desinformações (suposta neutralidade), o planejamento deficiente de execução, ligados ao alto custo e aos grandes impactos ambientais gerados, além de muitos fatos históricos e econômicos relacionados à implantação. Ao final, a sugestão vinda dos estudantes para visitação de espaço que contém riqueza histórica do município e, propriamente, da UHE Passo São João. Ressalto que a preparação do (a) da disciplina foi fundamental, a ponto de surgirem novos questionamentos; este estava apto à nova discussão, muito se deve à impregnação que houve da temática devido ao planejamento prévio.

Neste momento, discutiremos as inserções realizadas pelo (a) professor (a) da disciplina de Ciências (P2) com os mesmos estudantes do $9^{\circ}$ ano do ensino fundamental. A aula teve início, levando em conta os conhecimentos estipulados pelas respostas dos estudantes, abreviados no quadro acima. Assim começando com a análise de gráficos da matriz energética, mundial e brasileira, e suas diversas fontes de energia, que gerou discussão entre as energias de tipo renováveis e não renováveis. Pela análise nos gráficos, o Brasil possui maior produção de energia advindas de fontes renováveis, pois utiliza muitos dos recursos hídricos na produção de energia (sendo a água um recurso renovável). Questionamento que fiz ao P2, e este indicou o uso de livros didáticos no planejamento escolar e no planejamento desta aula. Os livros utilizados são de referência da nova Base Nacional Comum Curricular (BNCC), que entrará em vigor a partir do presente ano 2020. 
Passada a análise dos gráficos e ligando estes à grande produção de energia a partir da água, adentrou-se o tema das usinas hidrelétricas, especificamente a UHE Passo São João, indagando: "Como a água é usada na produção de energia elétrica"? (P2). Nesse momento, o (a) P2 distribuiu a um estudante um frasco de vidro fechado e iniciou a explicação de alguns conceitos, como força, intensidade, resistência e energia cinética, para comparar o funcionamento da usina hidrelétrica e contribuir na compreensão dos estudantes. Realmente sendo um exemplo que clarificou a compreensão, forma que demonstrou a aplicabilidade dos conceitos em diversas formas no decorrer do cotidiano, como a simples abertura de um frasco.

Na seguinte etapa da aula, tratou-se sobre as linhas de transmissão, novamente, destacando o planejamento conjunto e agora notável entre os (as) professores (as) das disciplinas de Ciências e Geografia, partindo de um mesmo conhecimento, porém, para alcançar diferentes aprendizagens. Para o ensino, utilizou-se o 'caminho' que a energia faz para chegar até nossas casas, de sua origem à usina, passando pelos conhecimentos de alta e baixa tensão, transformadores, geradores, acendendo novas questões dos estudantes como do "Por que 110 ou 220 volts dos aparelhos domésticos? (E8). Dúvida suscitada pela observação dos aparelhos elétricos de sua residência. Ou, o "Por que se utiliza a palavra Volts?" (E 13). "Então foi o cientista que descobriu”! (E9).

Assim, no momento seguinte, o (a) P2 distribuiu aos estudantes diversas “contas” de 'consumo' de energia elétrica, no mesmo momento o E9 questionou sobre "Como funciona o medidor de consumo? Percebendo a necessidade, o (a) P2 levou os estudantes até o medidor da escola e explicou seu funcionamento, adentrando no conteúdo unidades de mediadas (KW/h), utilizando a conta do 'consumo' anteriormente distribuída, realizando a interpretação dos dados apresentados e reproduzindo de forma explicativa, realizando cálculos para alcançar os valores finais que chegam até o consumidor como: taxa cobrada pela empresa, $\mathrm{KW} / \mathrm{h}$ 'consumidos', adicional por bandeira, este último, provocando maiores questionamentos, do porquê das cores, provocando novamente a explanação do (a) P2, que elucidou os estudantes sobre o Sistema de Bandeiras Tarifárias, relacionando o alto 'consumo' de energia em determinadas épocas do ano em nosso estado, acionando diferentes formas/fontes de 'produção' de energia (fontes com maior 'gasto'): “Aumentando o custo repassado aos consumidores”. (P2). Fato que novamente levou à continuidade na realização dos cálculos, agora sobre taxa cobrada pela empresa, já debatida em aulas da disciplina de Geografia, fato lembrado pelos estudantes.

No desenvolvimento de atividades sobre os cálculos descritos acima, o (a) P2 notou certas dificuldades dos estudantes em sua realização, propondo uma diferente metodologia de cálculo, que fosse de melhor compreensão a eles para próxima aula. Demonstrando serem planejamentos abertos ao processo de replanejamento de acordo com o contato dos estudantes em suas aulas, dando atenção a suas dificuldades, estando atento a eles e "as dificuldades que encontram na assimilação dos conhecimentos” (LIBÂNEO, 2013, P. 275). Enfatizando também que ensinar exige "bom-senso” na “orientação de atividades”, como no caso, em que o (a) P2 denotou a dificuldade dos estudantes na realização dos cálculos (FREIRE, 2020, p. 60).

Nestas primeiras aulas da disciplina de ciências, notou-se a diversidade de conteúdos subordinados ao tema (AULER; DALMOLIN; FENALTI, 2009), e todos emergentes da problematização levantada pelos estudantes, o que destaca a importância do planejamento prévio realizado pelos (as) professores (as), resultado que é observado em relação aos próprios estudantes, que estabelecem similaridades entre os conhecimentos, porém abordados nas diferentes disciplinas, com diferentes perspectivas, mas intrinsecamente ligados. A presença do livro didático segue sendo muito forte, como constatado, influenciando a prática em sala de aula, no entanto apresentado pelo (a) P2 como um auxiliar do (a) professor (a) nesse processo.

Outro fator importante foi o uso de práticas em sala de aula, aplicado ao cotidiano dos estudantes, demonstrando que um simples experimento contém muitos elementos similares a diferentes abordagens, colaborando na compreensão conceitual e, sobretudo, a compreensão do processo de tomada de decisões pelos estudantes, como no uso consciente de energia elétrica, devido ao seu alto custo (constatado muitas vezes e levantado no decorrer da aula pelos estudantes), tanto que observado o alto consumo na escola (uso de ar condicionado, lâmpadas...). E fora que está o dia inteiro ligado"! (E11). Aspectos que suscitou a complementação de conhecimentos para os próximos encontros, como o 'consumo' diário e posteriormente mensal dos aparelhos domésticos, sua respectiva potência e como calcular este 'consumo’ em suas residências.

Conforme já observado anteriormente, a dificuldade de estudantes na compreensão do cálculo presente na conta de energia elétrica, demandou uma retomada de conteúdo nessa nova aula, o (a) P2 propôs a elaboração de uma diferente metodologia para efetivar o cálculo, dividindo em três etapas, $1^{\circ}$ : 
kWh consumidos mensalmente, multiplicando pelo uso do sistema (tarifa cobrada); $2^{\circ}$ : 'consumo' efetivo de energia (de cada aparelho elétrico) $3^{\circ}$; adicional de bandeira/tarifa multiplicado por cada $100 \mathrm{KWH}$, o que rendeu três resultados, que somados resulta no consumo/valor final repassado aos consumidores. A metodologia diferenciada como auxílio na compreensão do cálculo e na interpretação da conta obteve êxito diante dos estudantes, pois utilizou diferentes métodos, e notou-se facilidade de interpretação no modelo de cálculo elaborado pelo (a) P2, modelo aparentemente simples, mas que, fragmentado, proporcionou compreensão dos valores e taxas cobradas pela empresa responsável na distribuição de energia elétrica.

Outro conteúdo abordado e relacionado às contas de energia elétrica, foi a taxa cobrada pelas faixas, que despertou curiosidade quanto a isso. O (a) P2 utilizou conteúdos já trabalhados em aulas passadas, principalmente sobre fontes de energia renováveis e não renováveis, questionando qual destas fontes seria de maior custo, prontamente e unanimemente, os estudantes apontaram fontes não renováveis como o petróleo e a energia nuclear, resultados adquiridos pela pesquisa, solicitada em aula anterior, relacionando a época em que a bandeira vermelha acrescia no valor das contas, como o verão. Foi feita a relação na qual os estudantes apontaram o maior uso de ar condicionado na escola, debatendo até a influência ou não do horário de verão como uma prática de reduzir o 'consumo', que no ano (2019) foi cancelado pelo governo federal, levantou-se uma pequena "enquete” de quem optasse a favor ou contra.

Outro ponto que chamou a atenção dos estudantes, foi quanto aos impostos municipais pagos referentes à luz pública, encontrados na conta de energia elétrica, "Mas como a gente paga, e não tem luz na rua"! (E13). Apontando lugares próximos a suas residências com o mesmo problema, problema em que o (a) P2 aconselhou a efetivar tais reclamações, e ajustes na iluminação pública, nos órgãos municipais, estes acessíveis à comunidade. Outra fonte de energia citada na pesquisa foi a solar, disponível em algumas residências de estudantes, seguida da explicação técnica e a explicação do sistema de compensação de energia elétrica e os créditos energéticos, de pouco conhecimento para os estudantes, apesar de fazer parte do cotidiano de alguns deles, "Falaram que é limpa, e barata" (E3). Comentário que gerou a intervenção do (a) P2 descrevendo que, por ser fonte de energia de baixo custo, a mesma, também, apresenta impactos, "Uma não necessariamente anula a outra” (P2). Esses impactos foram listados pelos estudantes, juntamente como o (a) professor (a).

Em um segundo momento da aula, foi apresentada uma maquete desenvolvida pelo (a) P2 que reproduzia um projeto de instalação elétrica em uma residência semelhante ao dos estudantes. Após a explicação a turma, o (a) P2 dirigiu-se até à caixa de distribuição da escola, enfatizando sua funcionabilidade, na volta para sala havia diversos conteúdos para contribuir na explicação da distribuição de circuitos da maquete, mais especificamente da caixa de distribuição e seus disjuntores ou mais utilizados contemporaneamente, os fusíveis, os quais demandaram maior explanação como: corrente, metais, energia na forma de calor, ponto de fusão, dilatação de materiais, condutividade. Houve até a relação com uma problemática recorrente na escola, "Por isso cai a chave, quando estão todos os ar condicionados ligados"! (E2).

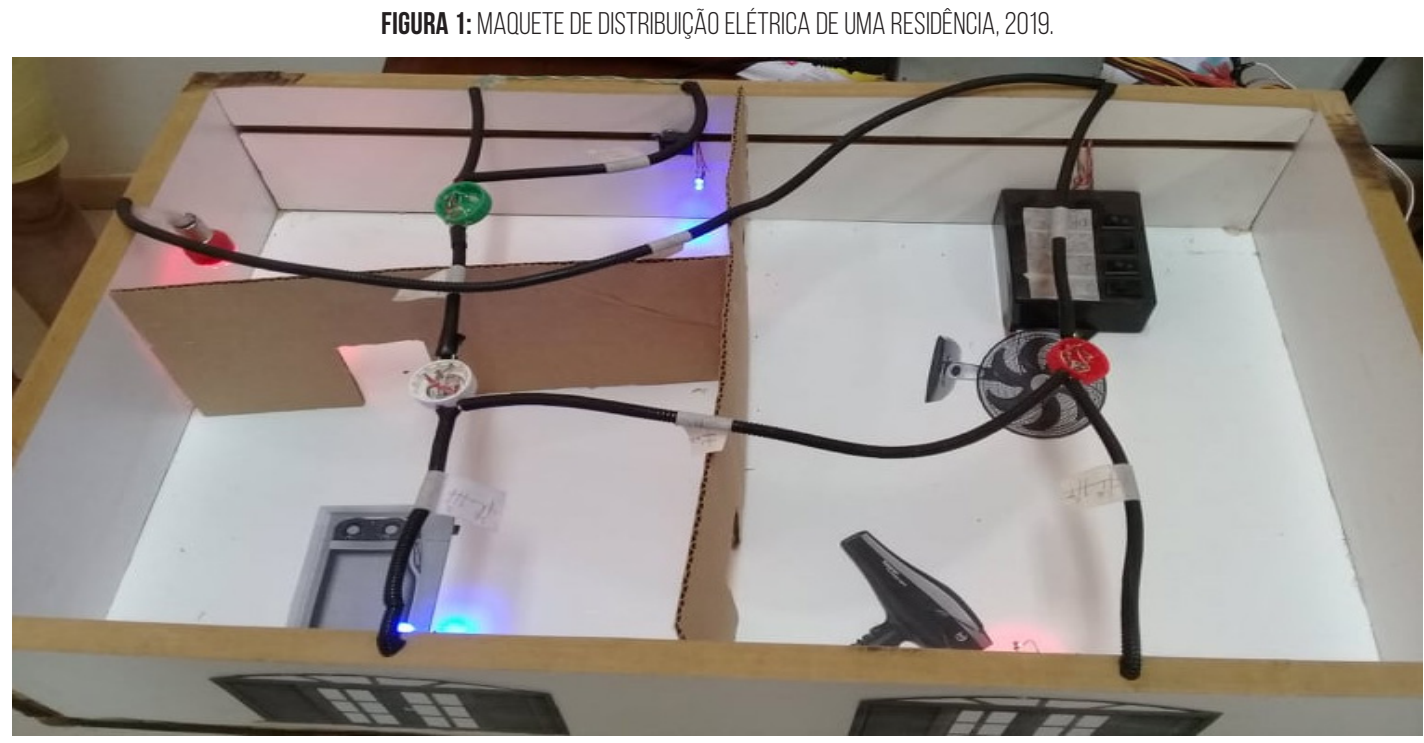

FONTE: SCHWAN, 2019 
A partir da observação da maquete, surgiu a primeira pergunta: "Uma chave só para o chuveiro"? (E1). Neste momento, o (a) P2 deu início à terceira etapa de seu planejamento, que trouxe consigo alguns eletrodomésticos como o chuveiro, torneira elétrica e lâmpadas do tipo incandescente, fluorescente e LED, problematizando a potência de cada objeto, primeiro, de modo que os estudantes apontassem as formas mais econômicas ou maiores consumidoras de energia. Cabe ressaltar o destaque dado pelo (a) P2 na evolução das pesquisas científicas das lâmpadas, diminuindo sua potência e custo, aumentando sua luminosidade, junto a problemáticas da lâmpada fluorescente a saúde dos seres humanos.

Introduziram-se fórmulas de cálculo de potência, tensão, corrente, trabalhando em conjunto a outros conteúdos como: sistema de unidades de medidas, conversão de unidades, Quilômetros (Km) em Metros (m); horas (h) em minutos (min). Ao final, foram propostas atividades, a fim de aprimorar a resolução de cálculos envolvendo potência, a quantidade de energia 'consumida' em determinado tempo e o valor final repassado ao consumidor de vários aparelhos elétricos presentes em suas residências. Houve grande conscientização dos estudantes quanto ao elevado custo em suas residências. E a importância de conhecimentos advindos de outras disciplinas, "Olha usando matemática em ciências"! (E4). Conhecimentos utilizados nas atividades como a resolução de equações. Após a atividade, houve reflexões de estudantes, devido à alta potência de alguns aparelhos como o chuveiro e motivo da necessidade de tanta energia. Levando, consequentemente, a perguntas sobre condutividade elétrica em água. "Porque o choque é tão grande no chuveiro" (E1).

Até o momento, e relatando especificamente a disciplina de ciências, foi na qual ocorreu o maior número de conteúdos correlacionados ao tema, conteúdos que emergiram da temática e da problematização estipulada em planejamento ou advindos da aula, mostrando que houve a provocação e motivação dos estudantes em conteúdos antes pertencentes à linha "dura” das ciências, que agora atribuído significado a eles a partir do seu cotidiano, característica da investigação temática a qual "[...] exige de seus sujeitos que vão descobrindo, no encadeamento dos temas significativos, a interpenetração dos problemas” (FREIRE, 1987, p. 64)

Demonstrando uma amplitude maior que a delimitada apenas a fatos estritamente alusivos à usina hidrelétrica, mas a problemáticas em sua distribuição. Cabe ressaltar a importância do replanejamento de atividades devido a sua complexidade inicial e à não compreensão pelos estudantes em um momento inicial, desenvolvendo metodologias que melhor se adéquam ao ensino e aprendizagem dos mesmos. Evidenciando que a problemática que se estabeleceu em um primeiro momento focada na usina hidrelétrica foi além do previsto, porém mantendo-se intrinsecamente conexa à central.

A última aula da disciplina de ciências elaborado (a) pelo (a) P2 consistiu em uma visita guiada ao interior do município de Roque Gonzales ${ }^{7}$, optou-se pela visitação de um biodigestor utilizado na produção de biogás, para contribuir no objetivo principal desta aula em conhecer formas diversificadas de 'produção' de energia, e o biogás mostrando-se como alternativa.

A produção de biogás a partir da matéria orgânica, "pode-se obter a geração de energia térmica por meio de sua combustão” (ALMEIDA; BRUNO, 2016, p. 61), matéria orgânica, advinda de animais da própria propriedade, tornava a residência autossuficiente, no consumo de gás para fins de cozinha e para os mais diversos propósitos. Surgiram diversas explanações e questionamentos, tanto de professores (as) e estudantes sobre o funcionamento e consequentemente da produção de gás: "Bactérias decompositoras, em ambiente anaeróbio”. (P2). "Gás metano, um gás altamente inflamável”. (P2). "Quando muda a temperatura, produz menos gás”? (E6). "Qual a quantidade de gás comprada no ano por vocês”? (E4). Após os questionamentos, as respostas do agricultor, dono da propriedade onde está o biodigestor, impressionou os estudantes, pois ele não havia comprado mais Gás liquefeito de petróleo (GLP) no comércio, o qual questionaram-se do "Porque todos não produzem gás"? (E8). Entrando em discussão o alto custo, mesmo reaproveitando e utilizando alguns materiais relativamente de fácil aquisição, mesmo assim o preço poderia ser superior a R \$ 4.000,00, indagou o proprietário do biodigestor. Preço considerado ainda alto por ele, levando em conta a situação econômica de alguns agricultores.

\footnotetext{
${ }^{7}$ Destacar que o município tem sua economia baseada na agricultura, e uma delas consiste na prática leiteira, portanto, propício para utilização de um biodigestor, que utiliza dejetos orgânicos (fezes de animais) para produção de gás (metano), que por meio de sua combustão, obtém-se energia térmica e essa energia pode ser convertida em elétrica.
} 


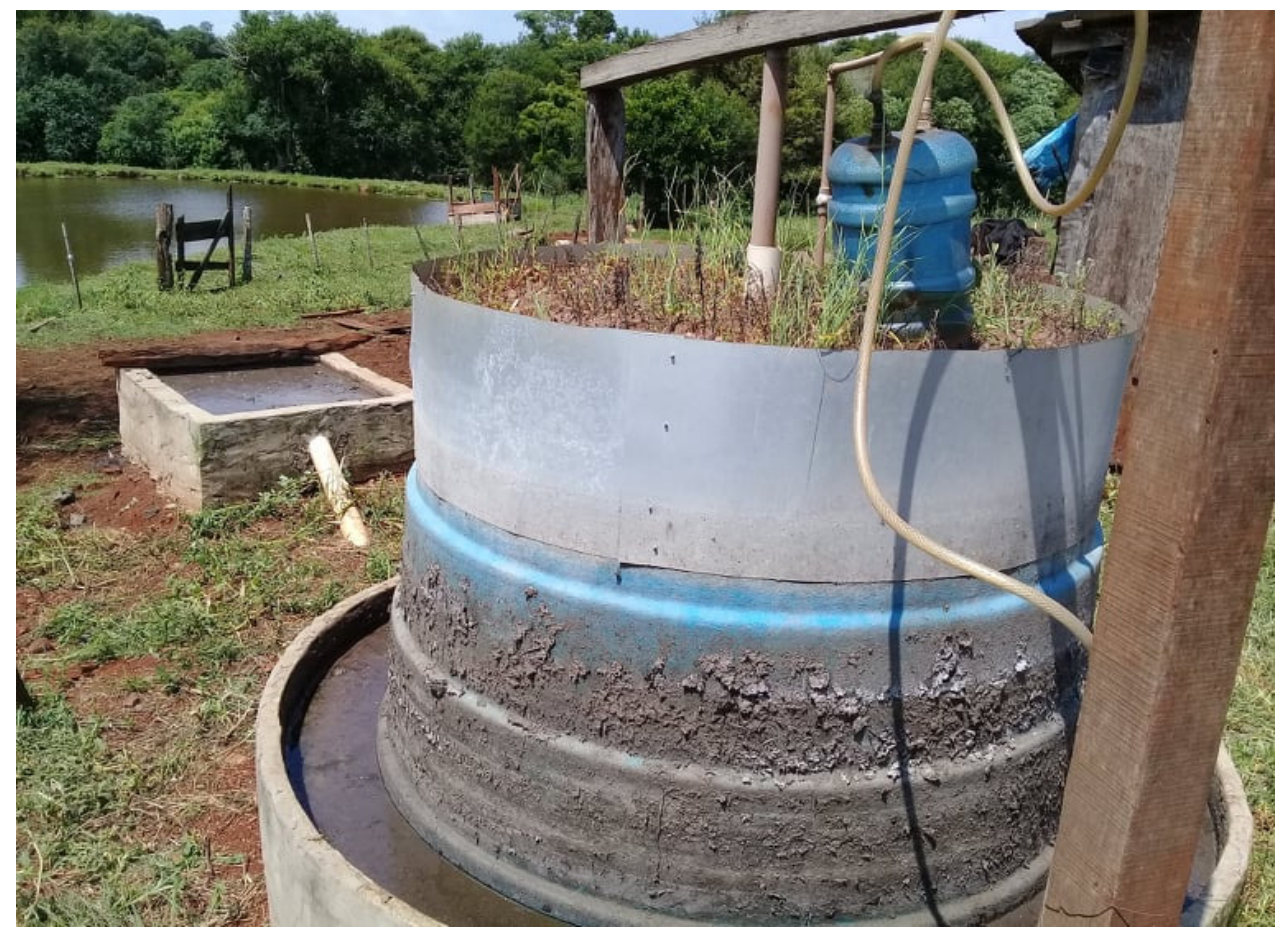

FONTE: SCHWAN, 2019

Nesta aula da disciplina de Ciências, podemos ressaltar um ponto muito importante da Investigação Temática freireana, além estabelecer um tema advindo de uma problemática vivencial dos estudantes. Este gerou conhecimentos que auxiliaram na sua compreensão, no caso do biodigestor, tratar-se de um conhecimento disponível e de fácil acesso, pertencente ao cotidiano dos (as) professores (as) que, anteriormente, em um currículo com definições de conhecimentos/conteúdos a priori, não se fazia possível e que nesta configuração curricular encontram-se disponíveis.

\section{CONSIDERAÇ̃̃ES}

Por meio deste conjunto de práticas que envolve esse relato, que estruturalmente está envolto por temas que tragam problemáticas reais da CT, marcados pela investigação do contexto vivido de docentes e discentes pela dinâmica freiriana, procurou auxiliar e estimular a participação de professores (as) na elaboração de planejamentos e, consequentemente, práticas capazes de fomentar a participação social de estudantes nos processos decisórios da CT, formando seres críticos e responsáveis, capazes de mudanças em seu mundo vivido, objetivo que acreditamos ter atingido, pois, além de estimulados, ambos professores demonstraram apropriação do tema investigado, o que deu condições para inserção de novos temas com a mesma característica contextual, que anteriormente, em um currículo de definições a priori, não se fazia possível.

Da mesma forma que os estudantes puderam emergirem de uma consciência ingênua para uma concepção crítica da realidade, através da aproximação entre os pressupostos de Freire e o enfoque CTS, que é baseada na "problematização" de tema de relevância social, rompendo com "situações-limites" estas que se apresentam ao homens como "determinante históricas, esmagadoras, em face das quais não lhes cabe outra alternativa, senão adaptar-se (FREIRE, 1987, p. 53), que no ato de problematizar os temas, visualizem-se soluções aos problemas e alcançando assim o "inédito viável”, de forma que se impõem a ação "libertadora" aos homens (FREIRE, 1987), e que assim possam "[...] tomar consciência da sua situação existencial e pudesse agir sobre ela para transformá-la em direção à construção de uma sociedade mais justa e igualitária” (SANTOS, 2008, p. 117). Com isso se evidencia que a dinâmica freireana é possível em espaços formais de educação. 
Deste modo, entendemos que a prática educativa com aproximações dos pressupostos freireanos ao enfoque CTS atingiu seus objetivos, proporcionando significações aos conhecimentos advindos da temática, pois os mesmos partiam de problemáticas sociais e ambientais de características vivenciais de professores e estudantes. Com isso, contribui-se na formação crítica e reflexiva, a qual possa estimular uma maior participação na tomada de decisões dos sujeitos envolvidos nesta prática.

\section{REFERÊNCIAS}

ALMEIDA, V. N. L. BRUNO, R. L. Biodigestor orgânico: geração de energia elétrica através de biogás. Revista Científica da FHO|UNIARARAS v. 4, n. 2/2016.

AULER, D. Alfabetização científico-tecnológica: um novo "paradigma”? ENSAIO - Pesquisa em Educação em Ciências. v. 5, n. 1, 2003.

AULER, D. Interações entre Ciência-Tecnologia-Sociedade no contexto da formação de professores de ciências. 2002. 258 f. Tese (Doutorado em Educação) - Centro de Educação, Universidade Federal de Santa Catarina, Florianópolis, 2002.

AULER, D. Articulação Entre Pressupostos do Educador Paulo Freire e do Movimento CTS: Novos Caminhos Para a Educação em Ciências. CONTEXTO \& EDUCAÇÃO, v. 22 n. 77, 2007, p. 167188.

AULER, D. DALMOLIN, A. M. T. FENALTI, V. S. Abordagem Temática: natureza dos temas em Freire e no enfoque CTS. Alexandria, Florianópolis, Santa Catarina, v. 2, n. 1, p.67-84, 2009.

AULER, D. DELIZOICOV, D. Investigação de temas CTS no contexto do pensamento latino americano. Linhas Críticas, vol. 21, nº45, p. 275-296, 2015.

CARDOSO, O. R. DAMBRÓS, M. M. G. XAVIER, R. A.; WEISS, C. V. C. GAUER, N. P. A Utilização de SIG no Auxílio da Análise dos Impactos Ambientais Causados pelas Usinas Hidroelétricas Passo São João e São José Localizadas no Rio Ijuí - RS. Scientia Plena 11, 021701 (2015).

CARSON, R. Silent Spring. Boston, USE: Houghton Mifflin Company, 1962.

DAGNINO, R. Neutralidade da ciência e determinismo tecnológico: um debate sobre a tecnociência. Campinas, SP, Unicamp, p. 280, 2008.

DELIZOICOV, D. ANGOTTI, J. A. PERNAMBUCO, M. M. Ensino de ciências: fundamentos e métodos. São Paulo: Cortez, 2002.

FREIRE, P. Pedagogia da Autonomia: saberes necessários à prática educativa. $63^{\circ} \mathrm{Ed}$. Rio de Janeiro, Paz e Terra, 2020.

FREIRE, P. Pedagogia do Oprimido. 17ª Ed. Rio de Janeiro - RJ: Paz e Terra, 1987.

HOFFMANN, M. B. DUSO, L. Controvérsias sociocientíficas no ensino de ciências: aspectos da pesquisa brasileira publicada em periódicos. IX ANPED SUL. Seminário de pesquisa em educação da região sul, 2012.

KOLBERT, E. A Sexta Extinção: Uma história não natural. Rio de Janeiro - RJ: Intrínseca, 2014.

LIBÂNEO, J. C. Didática. 2. ed. São Paulo: Cortez, 2013.

PORLÁN, R. MARTÍN, J. El diário del professor: Un recurso para la investigacion. Sevilla: Díada Editora, 1997. 
REIS, P. A Discussão de Assuntos Controversos no Ensino das Ciências. Inovação, v. 12, p. 107-112, 1999.

ROSA, S. E.; STRIEDER, R. Dimensões da democratização da ciência-tecnologia no âmbito da educação CTS. Revista Insignare Scientia - RIS, v. 1, n. 2, 24 ago. 2018.

ROSO, C. C. AULER, D. A participação na construção do currículo: práticas educativas vinculadas ao movimento CTS. Ciênc. Educ., Bauru, v. 22, n. 2, p. 371-389, 2016.

ROSO, C.C. SANTOS, R.A. ROSA, S.E. AULER, D. Currículo temático fundamentado em FreireCTS: engajamento de professores de física em formação inicial. Revista Ensaio, Belo Horizonte. v.17, n. 2, p. 372-389, 2015.

SANTOS, R. A. A não neutralidade na perspectiva educacional ciência-tecnologia-sociedade. Dissertação (Mestrado) - Curso de Pós-Graduação em Educação, Universidade Federal de Santa Maria, Santa Maria, 2012.

SANTOS, R. A. Busca de uma participação social para além da avaliação de impactos da ciênciatecnologia na sociedade: sinalizações de práticas educativas cts. 2016. 205 f. Tese (Doutorado) - Curso de Programa de Pós-graduação em Educação, Universidade Federal de Santa Maria, Santa Maria, Rs, 2016.

SANTOS, R. A. AULER, D. Práticas educativas CTS: busca de uma participação social para além da avaliação de impactos da Ciência-Tecnologia na Sociedade. Ciência e Educação, Bauru, v. 25, n. 2, p. 485-503, 2019.

SANTOS, W. L. P. Educação científica humanística em uma perspectiva freireana: resgatando a função do ensino de CTS. Alexandria - Revista de Educação em Ciência e Tecnologia, Florianópolis, SC, v. 1, n. 1, p. 109-131, 2008.

SCHWAN, G.; SANTOS, R. A. Dimensionamentos curriculares de enfoque CTS no ensino de ciências na educação básica. Revista de Estudos e Pesquisas sobre Ensino Tecnológico (EDUCITEC), v. 6, e098120, 2020.

SILVA, T. T. Documentos de identidade: uma introdução às teorias do currículo. $2^{\mathrm{a}}$ Ed. Belo Horizonte - MG: Autêntica, 2005.

STRIEDER, R. B. Abordagem CTS e Ensino Médio: Espaços de Articulação. (Dissertação de Mestrado). Universidade de São Paulo. São Paulo. 2008.

STRIEDER, R. B. Abordagens CTS na educação científica no Brasil: Sentidos e perspectivas. 2012. Tese (Doutorado em Ciências) - Universidade de São Paulo, São Paulo, 2012. 